\title{
Factors Associated with the Presence of Extraintestinal Manifestations in Patients with Ulcerative Colitis in a Latin American Country
}

\author{
Jesús K. Yamamoto-Furusho Germán E. Sánchez-Morales \\ Inflammatory Bowel Disease Clinic, Department of Gastroenterology, Instituto Nacional de Ciencias Médicas y \\ Nutrición Salvador Zubiran, Mexico City, Mexico
}

\section{Keywords}

Extraintestinal manifestations - Inflammatory bowel disease · Ulcerative colitis

\begin{abstract}
Background and Aim: Ulcerative colitis (UC) is a subtype of inflammatory bowel disease that can develop extraintestinal manifestations (EIMs) in a subgroup of patients. The aim of this work was to study the frequency and clinical factors associated with the development of ElMs. Methods: We evaluated a total of 260 Mexican patients with confirmed UC who were followed retrospectively in order to identify the factors associated with the presence of EIMs. Results: The frequency of EIM was $55.8 \%$. The factors associated with the development of EIM were pancolitis ( $p=0.003, \mathrm{OR}=2.44,95 \% \mathrm{Cl}=$ $1.34-4.56)$ and previous colectomy $(p=0.024, \mathrm{OR}=7.54,95 \%$ $\mathrm{Cl}=1.20-60.44)$. A clinical course of initial activity and then long remission for $>5$ years was found to be a protective factor ( $p=0.002, \mathrm{OR}=0.31,95 \% \mathrm{Cl}=0.14-0.67)$. Conclusion: The frequency of EIM was $55.8 \%$ in our population, and the factors associated with their development were pancolitis and colectomy; meanwhile, a clinical course of initial activity and then long remission was a protector feature.
\end{abstract}

(c) 2020 The Author(s)

Published by S. Karger AG, Basel

\section{Introduction}

As many as $36-56 \%$ of patients with inflammatory bowel disease (IBD) have at least one extraintestinal manifestation (EIM) along the course of the disease, affecting mainly articular, ocular, hepatobiliary, hematologic and dermatologic levels. These EIMs might present before, after, or at the time of IBD diagnosis, even more, they could emerge several years after a proctocolectomy. Some of these EIMs have a negative impact in daily activities with a significant decrease in the life quality [1] setting the need for a multidisciplinary team in their diagnosis and treatment.

According to the relationship with ulcerative colitis (UC) activity, EIMs can be classified into 2 different groups: those who have a direct relationship with intestinal activity (i.e., pauciarticular arthritis and erythema nodosum) and those with an independent course from the underlying IBD activity that may suggest an autoimmune component (i.e., uveitis and ankylosing spondylitis); other manifestations like pyoderma gangrenosum might or might not be related with activity of IBD [2-4]. The pathophysiology process of EIMs is unknown; however, numerous mechanisms have been proposed, including genetic susceptibility, based on high concordance reported in siblings and first-degree relatives [5] aberrant self- karger@karger.com www.karger.com/iid

Karger $\stackrel{\text { ' }}{=}$

GOPEN ACCESS
(C) 2020 The Author(s)

Published by S. Karger AG, Basel

This is an Open Access article licensed under the Creative Commons Attribution-NonCommercial-4.0 International License (CC BY-NC) (http://www.karger.com/Services/OpenAccessLicense), applicable to the online version of the article only. Usage and distribution for commercial purposes requires written permission.
Jesús K. Yamamoto-Furusho

Department of Gastroenterology

Instituto Nacional de Ciencias Médicas y Nutrición Salvador Zubirán

Vasco de Quiroga 15, Colonia Sección XVI, Mexico City 14080 (Mexico) kazuofurusho@hotmail.com 
Fig. 1. Distribution of EIM in patients with ulcerative colitis. EIM, extraintestinal manifestation; PSC, primary sclerosing cholangitis; PG, pyoderma gangrenosum; AS, ankylosing spondylitis; EN, erythema nodosum.

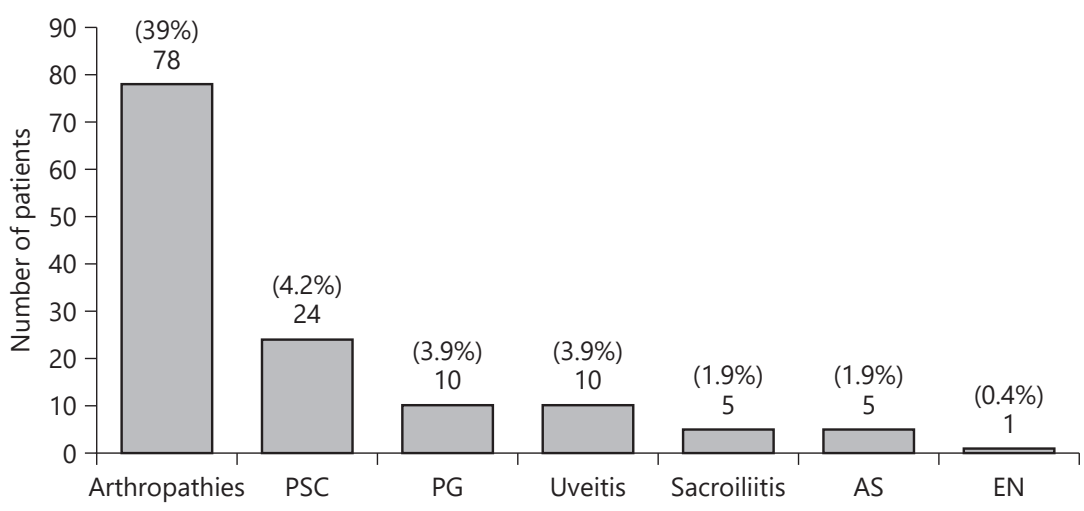

recognition and autoantibodies against shared proteins between colon epithelium and different target organs like biliary track, skin, eyes, and joints $[6,7]$. Some studies have shown the relationship between EIMs and some genes located in the major histocompatibility complex on chromosome 6, for instance, HLA B8/DR3, HLA

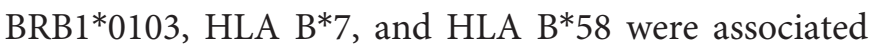
with primary sclerosing cholangitis, arthropathies, cutaneous, and ocular manifestations, respectively. Albeit ankylosing spondylitis has been linked with HLAB*27, this association is not as strong as in the absence of IBD [811]. The presence of IBD family history, active smoking, and positive perinuclear anti-neutrophilic cytoplasmic antibody have been associated with the development of EIMs along UC course.

It is well known that the recurrence of the same EIMs is common, and patients with one EIM have an increased risk for developing another one [8]. A positive association of arthritis with dermatologic and ophthalmologic complications has been observed, suggesting a common pathogenic mechanism [12]. The aim of this study was to determine the frequency of EIMs in patients with UC and the factors associated with its development.

\section{Methods}

\section{Patients}

Two hundred sixty Mexican patients with a diagnosis of UC confirmed by histology were studied. These patients were recruited from the Inflammatory Bowel Diseases Clinic at the National Institute of Medical Sciences and Nutrition in Mexico City during the period between January 1, 2007, and December 31, 2014.

Demographic, clinical, endoscopic, and histologic data were gathered from medical records and direct interviews. The variables evaluated included sex, current age, age at diagnosis, family history of IBD, disease duration, extent of disease, medical and surgi- cal treatment, clinical course, histologic activity, high-sensitive Creactive protein (hs-CRP), perinuclear anti-neutrophilic cytoplasmic antibody, history of appendectomy, current or past smoke history, and concomitant autoimmune disease.

For the determination of hs-CRP, we used a cutoff level of 0.36 $\mathrm{mg} / \mathrm{dL}$ since a previous study from Yamamoto-Furusho and colleges [13] showed had good correlation with histological activity. The extent of disease was defined according to the Montreal classification: proctitis (E1), left-sided colitis (E2), and extensive colitis (E3). The clinical course of disease was defined as active then inactive (first episode followed by a long-term remission for $>5$ years), intermittent (fewer of 2 relapses per year), and chronic activity (persistent activity despite medical treatment). For the clinical, endoscopic, and histologic evaluation, we used the Truelove-Witts, Mayo, and Riley indexes, respectively. The grade of activity was divided into 3 categories: mild, moderate, and severe. Regarding the EIM, we considered the most frequent EIMs such as peripheral arthropathies, primary sclerosing cholangitis, erythema nodosum, pyoderma gangrenosum, uveitis, sacroiliitis, and ankylosing spondylitis.

\section{Statistical Analysis}

Descriptive statistics are expressed as mean and standard deviation. Data were analyzed by Student's $t$ test for numerical variables and $\chi^{2}$ and Fisher's exact tests for categorical variables. When data were non-normally distributed, Wilcoxon's nonparametric rank sum test was used. Those risk factors with $p$ values $<0.1$ in the univariate analysis were included into the multivariate model. The results were expressed as odds ratio (OR) with corresponding $95 \%$ confidence interval (CI). Two-tailed tests for significance were used in all statistical analyses, and $p<0.05$ was considered statistically significant. The data analysis was performed with SPSS version 20 for Windows.

\section{Results}

A total of 260 patients with UC were included in the study, 125 females (48.10\%) and 135 males (51.90\%) with a mean current age of 44.6 years (range $16-80$ years old) 
Table 1. Clinical and demographic characteristics of patients with ulcerative colitis

\begin{tabular}{|c|c|}
\hline Characteristics & $\begin{array}{l}\text { Sample size } \\
(n=260)\end{array}$ \\
\hline \multicolumn{2}{|l|}{ Gender, $n(\%)$} \\
\hline Female & $125(48.10)$ \\
\hline Male & $135(51.90)$ \\
\hline Current age, mean (range), years & $44.66(16-80)$ \\
\hline Diagnosis age, mean (range), years & $31.62(6-65)$ \\
\hline Family history of IBD, $n(\%)$ & $6(2.30)$ \\
\hline Years of evolution of disease, mean (range) & $13.3(3-68)$ \\
\hline Extraintestinal manifestations, $n(\%)$ & $145(56.00)$ \\
\hline Appendectomy, $n(\%)$ & $12(4.60)$ \\
\hline Smoking, $n(\%)$ & $100(38.50)$ \\
\hline Concomitant autoimmune disease, $n(\%)$ & $24(9.20)$ \\
\hline \multicolumn{2}{|l|}{ Histologic activity, $n(\%)$} \\
\hline Remission & $56(21.5)$ \\
\hline Mild & $87(33.4)$ \\
\hline Moderate & $71(27.3)$ \\
\hline Severe & $46(17.8)$ \\
\hline Elevated hs-CRP (>0.36 mg/dL) & $127(48.84)$ \\
\hline Positive $\mathrm{p}$-ANCAs & $86(33.10)$ \\
\hline \multicolumn{2}{|l|}{ Extension of the disease, $n(\%)$} \\
\hline Extensive colitis & $204(78.50)$ \\
\hline Left-sided colitis & $13(5.00)$ \\
\hline Proctitis & $43(16.50)$ \\
\hline \multicolumn{2}{|l|}{ Clinical course, $n(\%)$} \\
\hline Active then inactive & $35(13.50)$ \\
\hline Intermittent activity & $202(77.70)$ \\
\hline Chronic activity & $23(8.80)$ \\
\hline \multicolumn{2}{|l|}{ Treatment, $n(\%)$} \\
\hline 5-ASA (oral or topical) & $234(91.90)$ \\
\hline Steroids & $62(23.80)$ \\
\hline Azathioprine & $76(29.20)$ \\
\hline Anti-TNF & $8(3.10)$ \\
\hline Colectomy & $10(3.80)$ \\
\hline
\end{tabular}

IBD, inflammatory bowel disease; hs-CRP, high-sensitive C-reactiveprotein; TNF, tumor necrosisfactor; ASA, aminosalicylic acid.

and a mean diagnosis age of 31.6 years (range 6-65 years ). EIM was present in 145 UC patients (55.8\%) with the following distribution: peripheral arthropathies 30\%, primary sclerosing cholangitis $9.20 \%$, pyoderma gangrenosum $3.90 \%$, uveitis $3.80 \%$, sacroiliitis $1.90 \%$, ankylosing spondylitis $1.90 \%$, and erythema nodosum $0.40 \%$, as shown in Figure 1.

The presence of peripheral arthropathies and erythema nodosum only had correlation with disease activity. The extent of disease was distributed as follows: extensive colitis (E3) in 78.5\%, left colitis (E2) in 5\%, and proctitis (E1) in $16.5 \%$. Regarding the clinical course, $13.5 \%$ had an active then inactive course, $77.7 \%$ had an intermittent activity, and $8.8 \%$ had chronic continual activity. Histological remission was present in 56 patients $(21.5 \%)$. The hs-CRP was elevated in 127 persons (48.84\%), and 86 patients $(33.1 \%)$ were positive for p-ANCAs. Concerning the medical treatment, the distribution was as follows: 5 -aminosalicylic acid $91.9 \%$, steroids $23.8 \%$, azathioprine $29.2 \%$, anti-tumor necrosis factor $3.1 \%$, and colectomy $3.80 \%$ as shown in Table 1 .

\section{Factors Associated with the Development of EIMs}

The clinical factors associated with the development of EIMs in Mexican patients with UC were an active then inactive clinical course $(p=0.002, \mathrm{OR}=0.31,95 \% \mathrm{CI}=$ $0.14-0.67)$, pancolitis $(p=0.003, \mathrm{OR}=2.44,95 \% \mathrm{CI}=$ $1.34-4.56)$, and the presence of colectomy ( $p=0.024$, $\mathrm{OR}=7.54,95 \% \mathrm{CI}=1.20-60.44)$. It is important to mention that peripheral arthropathies predicted the presence of other concomitant EIMs such as pyoderma gangrenosum $(p=0.01, \mathrm{OR}=8.44,95 \% \mathrm{CI}=1.6-66.9)$, uveitis $(p=0.01, \mathrm{OR}=8.44,95 \% \mathrm{CI}=1.6-66.9)$, and primary sclerosing cholangitis $(p=0.00003, \mathrm{OR}=18.8,95 \% \mathrm{CI}=$ $2.48-142.7$ ) in our population. Table 2 summarizes the factors associated from uni- and multivariate analysis. Other variables such as sex, current age, age at diagnosis, family history of IBD, disease duration, history of appendectomy, current or past smoke history, and concomitant autoimmune disease were not associated with the presence of EIMs.

\section{Discussion}

The finding of the present study was the frequency of $56 \%$ of EIMs in Mexican patients with UC, being the most common peripheral arthropathy (30\%) followed by PSC (9.20\%), uveitis (3.8\%), pyoderma gangrenosum (3.8\%), sacroiliitis $(1.90 \%)$, ankylosing spondylitis $(1.90 \%)$, and erythema nodosum $(0.40 \%)$ The overall frequency is in accordance with other populations from Europe and North America [14], although it is increased compared with a previous evaluation of the period from 1986 to 2007 by Yamamoto-Furusho [15] where the frequency was $41.5 \%$. Concerning peripheral arthropathies, the literature describes an occurrence of $30 \%$, which is in agreement with our findings [16]. On the other hand, several studies have shown a PSC frequency between 2 and 7.5\% [17] which is lower than our population. It is important to mention that there is a reference bias because our hospital is a tertiary care center. 
Table 2. Univariate and multivariate analysis for characteristics associated with the presence of extraintestinal manifestations

\begin{tabular}{lllcc}
\hline Variable & $\begin{array}{l}\text { Univariate } \\
p \text { value }\end{array}$ & $\begin{array}{l}\text { Multivariate } \\
p \text { value }\end{array}$ & OR & 95\% CI \\
\hline Peripheral arthropathies & 0.00003 & 0.00003 & 132.7 & $18-976.2$ \\
PSC & 0.0003 & 0.0003 & 18.8 & $2.48-142.7$ \\
Active-inactive clinical course & 0.002 & 0.002 & 0.31 & $0.14-0.67$ \\
Pancolitis & 0.003 & 0.003 & 2.44 & $1.34-4.56$ \\
Pyoderma gangrenosum & 0.001 & 0.010 & 8.44 & $1.6-66.9$ \\
Uveitis & 0.001 & 0.010 & 8.44 & $1.6-66.9$ \\
History of colectomy & 0.022 & 0.024 & 7.54 & $1.20-60.44$ \\
Ankylosing spondylitis & 0.058 & 0.060 & 4.96 & $0.58-41.52$ \\
Use of anti-TNF & 0.066 & 0.067 & 5.78 & $0.78-44.6$ \\
Elevated hs-CRP & 0.070 & 0.074 & 1.48 & $0.89-2.44$ \\
Positive p-ANCAs & 0.070 & 0.111 & 1.53 & $0.90-2.61$ \\
Use of steroids & 0.070 & 0.113 & 1.61 & $0.89-2.90$ \\
Intermittent clinical course & 0.073 & 0.107 & 1.61 & $0.89-2.90$ \\
Female gender & 0.096 & 0.191 & 1.42 & $0.87-2.33$ \\
\hline
\end{tabular}

PSC, primary sclerosing cholangitis; TNF, tumor necrosis factor; hs-CRP, high-sensitive C-reactive protein.

This work showed that the frequency of pyoderma gangrenosum was $3.8 \%$, which is over the $0.6-2.2 \%$ reported in other studies [18], although some other reports exposed higher frequencies even of $10 \%$ [19]. In the case of erythema nodosum, the occurrence in our sample was $1 \%$ compared with $4-6 \%$ presented on other studies [18, 19]. We found that the frequency of uveitis was $(3.8 \%)$ similar to reported in other populations between 2 and $6 \%$ [20]. Since sacroiliitis use to be an asymptomatic and non-progressive manifestation, there are different frequency reports in the literature; moreover, depending on the imaging method used to detect it, occurrence might vary widely. A distinct scenario is observed in ankylosing spondylitis, with a reported frequency of $5-10 \%$, where the severe pain and progressive damage aid to the diagnosis [21]. In this study, the frequency of sacroiliitis and ankylosing spondylitis was $1.9 \%$ for each one.

In the present study, the strongest factor associated with the presence of EIMs was the existence of another EIM, especially arthropathies $(p=0.000003, \mathrm{OR}=132.7$, $95 \% \mathrm{CI}=18.0-976.2)$ and followed in importance by primary sclerosing cholangitis ( $p=0.00003, \mathrm{OR}=18.8,95 \%$ $\mathrm{CI}=2.48-142.7)$, pyoderma gangrenosum $(p=0.01$, OR $=8.44,95 \% \mathrm{CI}=1.6-66.9)$, and uveitis $(p=0.01, \mathrm{OR}=$ 8.44, 95\% CI $=1.6-66.9$ ), These findings are comparable with those presented by Veloso et al. [12, 22] who described that arthritis had a significant association with concomitant dermatologic and ocular manifestations. All these data support the hypothesis of a common inflam- matory pathway known as the joint-gut axis where gut epithelium lymphocytes are recruited into the synovial due to structural shared antigen proteins $[23,24]$.

Furthermore, features like active then inactive clinical course $(p=0.002$, OR $=0.31,95 \% \mathrm{CI}=0.14-0.67)$, pancolitis $(p=0.003, \mathrm{OR}=2.44,95 \% \mathrm{CI}=1.34-4.56)$, and the presence of colectomy $(p=0.024$, OR $=7.54,95 \% \mathrm{CI}=$ 1.20-60.44) were the most important factors associated with EIMs bracing the role of the degree and extension of inflammation in the pathogenesis of the EIMs [25]. An active then inactive clinical course protects against EIMs compared to pancolitis and presence of colectomy that were associated with the development of EIMs in our population. Nevertheless, inflammatory process does not explain every case of EIMs so that there should be other physiologic pathways in the genesis of these manifestations. In conclusion, the frequency of EIMs was 55.8\%, and the factors associated were pancolitis, presence of colectomy, concomitant EIM, and the clinical course of disease characterized by initial activity and then long-remission.

\section{Statement of Ethics}

This work was performed according to the principles expressed in the Declaration of Helsinki, 1989. The study was approved by the ethical committee in our institution (Ref. 1037) and written informed consent was obtained from all patients recruited in this study. 


\section{Conflict of Interest Statement}

The authors have no conflicts of interest to disclose.

\section{Funding Sources}

The authors did not receive any funding.

\section{Author Contributions}

Jesus K. Yamamoto-Furusho provided the research idea, directed, performed data analysis, and prepared the manuscript. German E. Sanchez-Morales performed the review of the clinical medical records, performed the data base, and prepared the manuscript.

\section{References}

1 Ardizzone S, Puttini PS, Cassinotti A, Porro GB. Extraintestinal manifestations of inflammatory bowel disease. Dig Liver Dis. 2008; 40(Suppl 2):S253-9.

2 Bernstein CN, Blanchard JF, Rawsthorne P, $\mathrm{Yu}$ N. The prevalence of extraintestinal diseases in inflammatory bowel disease: a population-based study. Am J Gastroenterol. 2001; 96(4):1116-22.

3 Orchard TR, Wordsworth BP, Jewell DP. Peripheral arthropathies in inflammatory bowel disease: their articular distribution and natural history. Gut. 1998;42(3):387-91.

4 Orchard TR, Chua CN, Ahmad T, Cheng H, Welsh KI, Jewell DP. Uveitis and erythema nodosum in inflammatory bowel disease: clinical features and the role of HLA genes. Gastroenterology. 2002;123(3):714-8.

5 Satsangi J, Grootscholten C, Holt H, Jewell DP. Clinical patterns of familial inflammatory bowel disease. Gut. 1996;38(5):738-41.

6 Salmi M, Jalkanen S. Human leukocyte subpopulations from inflamed gut bind to joint vasculature using distinct sets of adhesion molecules. J Immunol. 2001;166(7):4650-7.

7 Van Praet L, Jacques P, Van den Bosch F, Elewaut $\mathrm{D}$. The transition of acute to chronic bowel inflammation in spondyloarthritis. Nat Rev Rheumatol. 2012;8(5):288-95.

8 Ott C, Schölmerich J. Extraintestinal manifestations and complications in IBD. Nat Rey Gastroenterol Hepatol. 2013;10(10):585-95.

9 de Vlam K, Mielants H, Cuvelier C, De Keyser F, Veys EM, De Vos M. Spondyloarthropathy is underestimated in inflammatory bowel disease: prevalence and HLA association. J Rheumatol. 2000;27(12):2860-5.
10 Orchard TR, Thiyagaraja S, Welsh KI, Wordsworth BP, Hill Gaston JS, Jewell DP. Clinical phenotype is related to HLA genotype in the peripheral arthropathies of inflammatory bowel disease. Gastroenterology. 2000;118(2): 274-8.

11 Steer S, Jones H, Hibbert J, Kondeatis E, Vaughan R, Sanderson J, et al. Low back pain, sacroiliitis, and the relationship with HLAB27 in Crohn's disease. J Rheumatol. 2003; 30(3):518-22.

12 Veloso FT, Carvalho J, Magro F. Immune-related systemic manifestations of inflammatory bowel disease. A prospective study of 792 patients. J Clin Gastroenterol. 1996;23(1):2934.

13 Yamamoto-Furusho JK, Camacho-Escobedo J, Téllez-Avila F, Barreto R. [Serum levels of beta2 microglobulin and ultrasensitive c-reactive protein as markers of histological activity in ulcerative colitis]. Gac Med Mex. 2010; 146(1):31-5.

14 Ricart E, Panaccione R, Loftus EV, Tremaine WJ, Harmsen WS, Zinsmeister AR, et al. Autoimmune disorders and extraintestinal manifestations in first-degree familial and sporadic inflammatory bowel disease: a case-control study. Inflamm Bowel Dis. 2004;10(3):20714.

15 Yamamoto-Furusho JK. Clinical epidemiology of ulcerative colitis in Mexico: a single hospital-based study in a 20-year period (1987-2006). J Clin Gastroenterol. 2009; 43(3):221-4.

16 Palm Ø, Moum B, Jahnsen J, Gran JT. The prevalence and incidence of peripheral arthritis in patients with inflammatory bowel disease, a prospective population-based study (the IBSEN study). Rheumatology. 2001; 40(11):1256-61.
17 Navaneethan U, Shen B. Hepatopancreatobiliary manifestations and complications associated with inflammatory bowel disease. Inflamm Bowel Dis. 2010;16(9):1598-619.

18 Farhi D, Cosnes J, Zizi N, Chosidow O, Seksik $\mathrm{P}$, Beaugerie L, et al. Significance of erythema nodosum and pyoderma gangrenosum in inflammatory bowel diseases: a cohort study of 2402 patients. Medicine. 2008;87(5):281-93.

19 Thrash B, Patel M, Shah KR, Boland CR, Menter A. Cutaneous manifestations of gastrointestinal disease: part II. J Am Acad Dermatol. 2013;68(2):211-6.

20 Trost LB, McDonnell JK. Important cutaneous manifestations of inflammatory bowel disease. Postgrad Med J. 2005;81(959):580-5.

21 Mady R, Grover W, Butrus S. Ocular complications of inflammatory bowel disease. ScientificWorldJournal. 2015;2015:438402.

22 Trikudanathan G, Venkatesh PG, Navaneethan U. Diagnosis and therapeutic management of extra-intestinal manifestations of inflammatory bowel disease. Drugs. 2012; 72(18):2333-49.

23 Lakatos PL, Lakatos L, Kiss LS, Peyrin-Biroulet L, Schoepfer A, Vavricka S. Treatment of extraintestinal manifestations in inflammatory bowel disease. Digestion. 2012;86(Suppl 1):28-35.

24 Brakenhoff LK, van der Heijde DM, Hommes DW, Huizinga TW, Fidder HH. The joint-gut axis in inflammatory bowel diseases. J Crohns Colitis. 2010;4(3):257-68.

25 May E, Märker-Hermann E, Wittig BM, Zeitz $\mathrm{M}$, Meyer zum Büschenfelde $\mathrm{KH}$, Buschenfelde KH, Duchmann R. Identical T-cell expansions in the colon mucosa and the synovium of a patient with enterogenic spondyloarthropathy. Gastroenterology. 2000;119(6): 1745-55. 